\title{
Cutaneous T-cell lymphomas with pathogenic somatic mutations and absence of detectable clonal T-cell receptor gene rearrangement: two case reports
}

Rebecca Rojansky ${ }^{1}$, Sebastian Fernandez-Pol ${ }^{1}$, Erica Wang ${ }^{2}$, Kerri E. Rieger ${ }^{1,2}$, Roberto A. Novoa ${ }^{1,2}$, James L. Zehnder ${ }^{1,3}$, Christian A. Kunder ${ }^{1}$, Youn H. Kim², ${ }^{2,}$ Michael S. Khodadoust ${ }^{2,4}$ and Ryanne A. Brown ${ }^{1,2,5^{*}}$ (D)

\begin{abstract}
Background: Cutaneous T-cell lymphomas (CTCL) are a heterogeneous group of extranodal non-Hodgkin lymphomas for which diagnosis can be challenging given the potential for overlap with inflammatory dermatoses. Current diagnostic criteria for CTCL incorporate clinical and histopathologic findings as well as results of T-cell receptor (TCR) gene sequencing. Molecular interrogation of TCR genes, TRG and TRB, has proven to be a critical tool for confirming diagnoses of $C T C L$ and for disease tracking after initiation of therapy or after stem cell transplant. Methods for confirming a diagnosis of lymphoma in the absence of TCR gene clonality are lacking. We present two patients with CTCL with pathogenic somatic mutations in the absence of TRG and TRB clonality.

Case presentations: Case 1: A 38-year-old male had a 19-year history of a diffuse skin rash with papulosquamous, granulomatous, and verrucous features and progressive ulcerated plaques and tumors demonstrating an atypical CD4+ Tcell infiltrate with expression of cytotoxic markers CD56, TIA-1, granzyme, and perforin on histopathology. No definitive evidence for T-cell clonality was detected by conventional PCR of 6 biopsies or by next-generation sequencing (NGS) of 14 biopsies. Somatic mutational profiling of a skin biopsy revealed pathogenic mutations in PIKC3D and TERT promoter hotspots, confirming the presence of a clonal process. Case 2: A 69-year-old male with a 13-year history of progressive, diffuse hypertrophic and eroded plaques showed an atypical CD4+ T-cell infiltrate with subset expression of TIA-1 and granzyme on histopathology. No TCR clonality was detected by TCR-NGS of 6 biopsies. Somatic mutational profiling of a skin biopsy detected a pathogenic mutation in TP53, confirming the presence of a clonal process.

Conclusions: These cases highlight how detection of pathogenic somatic mutations can confirm a diagnosis of lymphoma in a clinically and histopathologically suspicious cutaneous lymphoid proliferation without detectable TCR clonality.
\end{abstract}

Keywords: Lymphoma, Mycosis fungoides, T-cell receptor, Clonality, Next-generation sequencing, case report

\footnotetext{
* Correspondence: rbrown85@stanford.edu

'Department of Pathology, Stanford Medicine, Stanford, CA 94305, USA

2Department of Dermatology, Stanford Medicine, Stanford, CA 94305, USA

Full list of author information is available at the end of the article
}

\section{$\triangle B M C$}

(c) The Author(s). 2020 Open Access This article is licensed under a Creative Commons Attribution 4.0 International License, which permits use, sharing, adaptation, distribution and reproduction in any medium or format, as long as you give appropriate credit to the original author(s) and the source, provide a link to the Creative Commons licence, and indicate if changes were made. The images or other third party material in this article are included in the article's Creative Commons licence, unless indicated otherwise in a credit line to the material. If material is not included in the article's Creative Commons licence and your intended use is not permitted by statutory regulation or exceeds the permitted use, you will need to obtain permission directly from the copyright holder. To view a copy of this licence, visit http://creativecommons.org/licenses/by/4.0/ The Creative Commons Public Domain Dedication waiver (http://creativecommons.org/publicdomain/zero/1.0/) applies to the data made available in this article, unless otherwise stated in a credit line to the data. 


\section{Background}

Cutaneous T-cell lymphomas (CTCL) account for the majority (up to $75 \%$ ) of primary cutaneous lymphomas and are designated according to the updated WHOEORTC 2018 classification [1]. Diagnosis of CTCL requires integration of clinical, histopathologic, and molecular findings, the latter of which includes detection of clonal T-cell receptor (TCR) gene rearrangements via interrogation of TCR $\beta(T R B)$ and $\mathrm{TCR} \gamma(T R G)$ genes. A majority of mature $\mathrm{T}$-cell malignancies express membranous CD3 in complex with TCR [2]. TCR gene rearrangement occurs exclusively during thymic T-cell development to facilitate diverse antigen recognition and not in mature circulating $\mathrm{T}$-cells, so the detection of TCR monoclonality generally supports a clonal process such as T-cell lymphoma over an inflammatory disorder $[3,4]$. TCR clonality can also indicate T-cell origin in a lymphoid process of unknown lineage, reveal a clonal $\mathrm{T}$ cell proliferation in the background of another malignant process, serve as a marker for minimal residual disease (MRD) testing, or indicate common origin of distinct lesions [5]. Even when present, however, the definition and significance of TCR clonality remains subject to interpretation, especially when referring to the results of conventional polymerase chain reaction (PCR)-based clonality testing [6]. Some inflammatory dermatoses with benign clinical course such as pityriasis lichenoides have been shown to demonstrate TCR

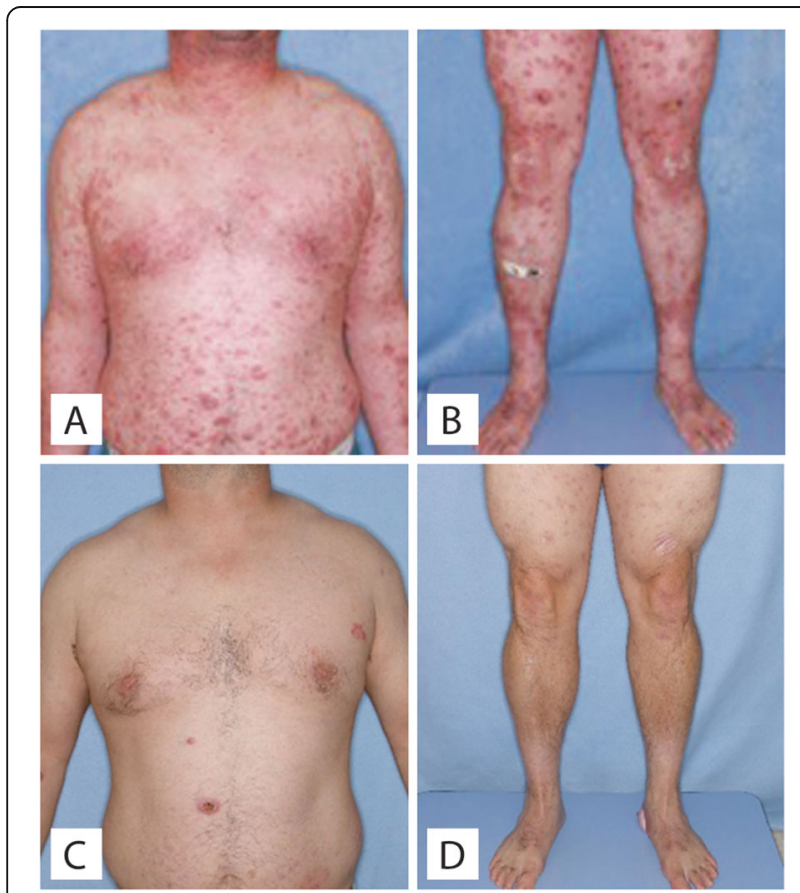

Fig. 1 Clinical photos of Case 1. a-b, Upon presentation at our institution. Erythematous scaly flat-topped papules and plaques. c-d Improvement after therapy clonality [7]. Therefore, while TCR clonality is a crucial part of diagnosing peripheral T-cell lymphomas, it must be interpreted carefully and in the context of the entire clinical and histopathologic picture. Here we present two CTCL cases from our institution with polyclonal TCR by conventional PCR and high throughput nextgeneration sequencing (NGS). Both cases demonstrated clonal pathogenic somatic mutations, confirming their clonal origin and thus the diagnosis of lymphoma.

\section{Case presentations}

\section{Case 1}

A 38-year-old previously healthy male presented to an outside institution at age 19 with an erythematous macular abdominal rash, which progressed to diffuse cutaneous involvement over 12 years with eventual development of polymorphic clinical features, including papulosquamous, granulomatous, and verrucous skin lesions with progressive ulcerated plaques and tumors (Fig. 1a-b). He showed some improvement with total

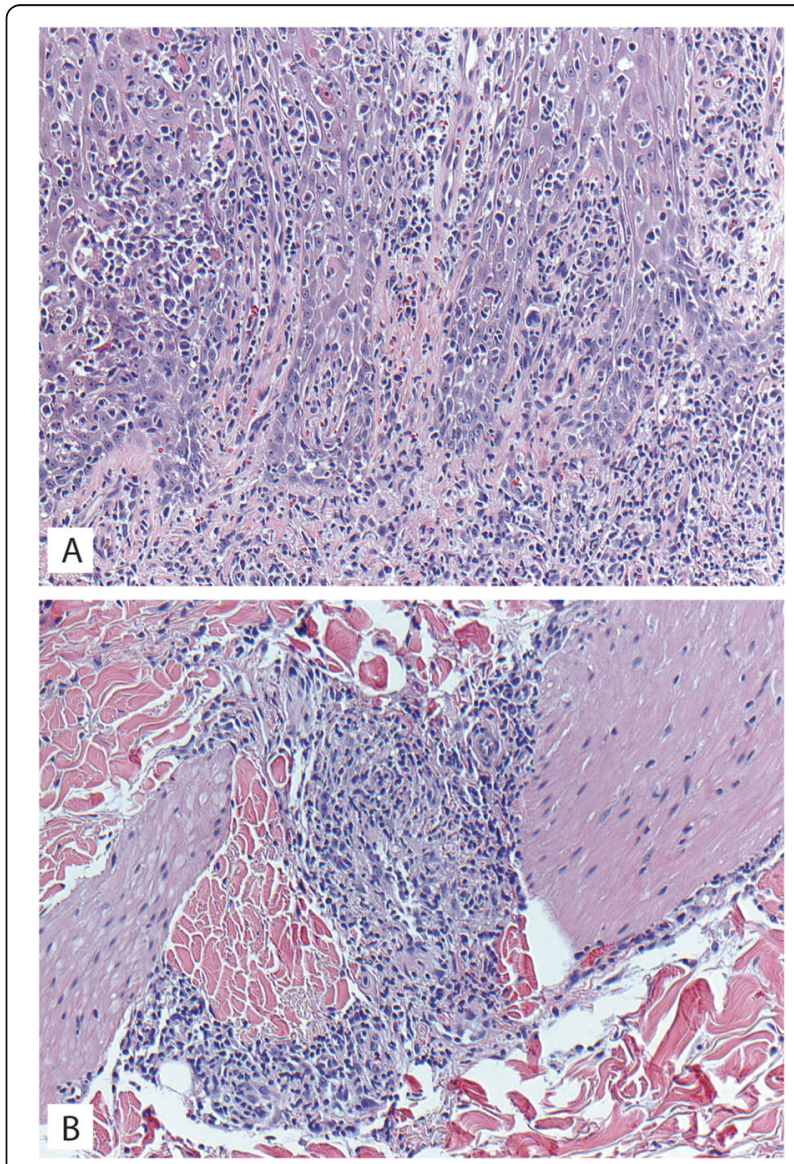

Fig. 2 Microscopic images of Case 1 histopathology. a Biopsy of left thigh lesion showing dense lichenoid and epidermotropic infiltrate of small to medium size lymphocytes with irregular nuclear contours; H\&E 200X. b Biopsy of left thigh lesion showing a nodular granulomatous and lymphocytic dermal infiltrate centered on a vessel; H\&E 200X 


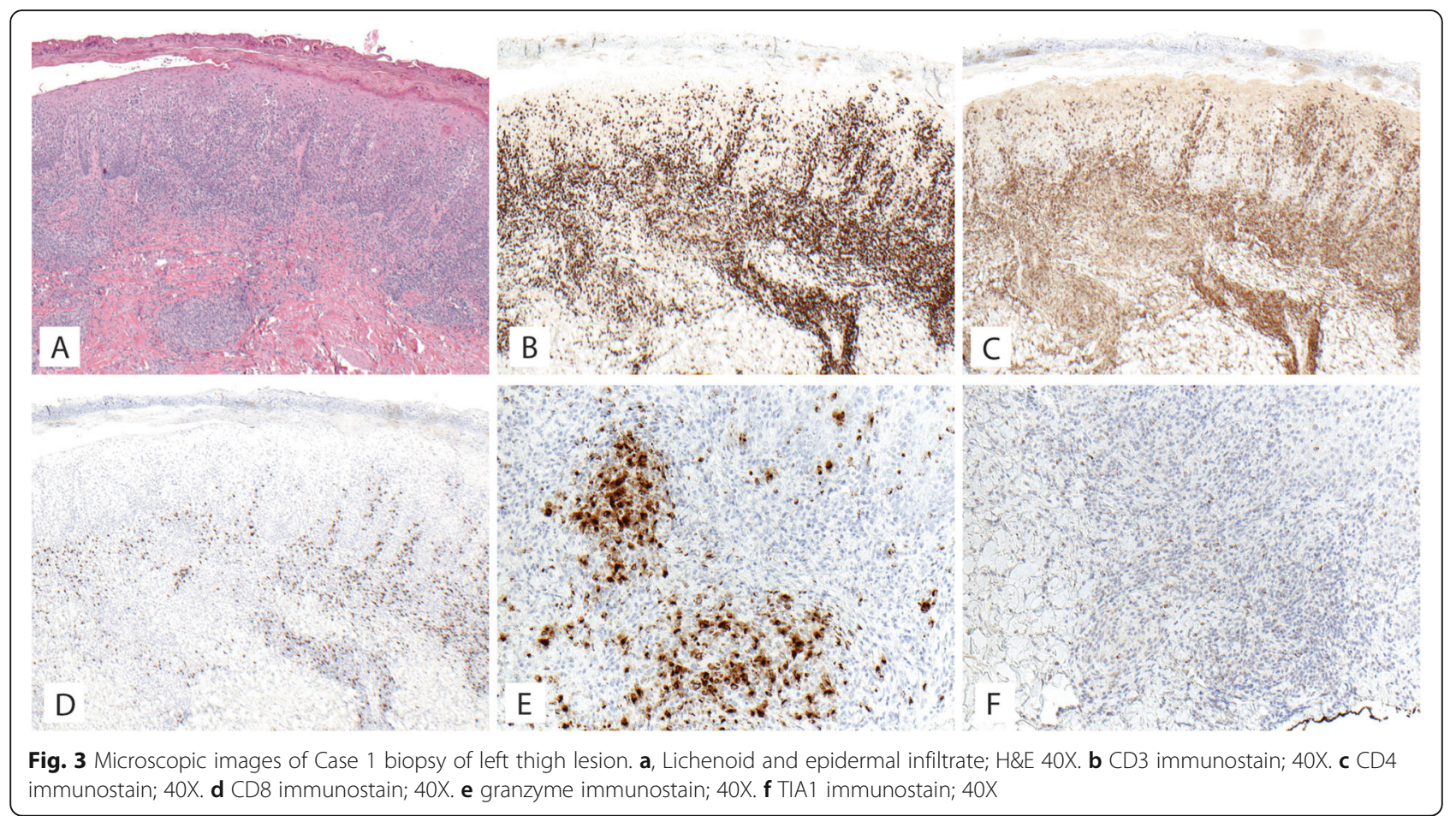

skin electron beam therapy and localized radiotherapy but ultimately progressed. His disease was persistent despite numerous chemotherapeutic and immunomodulatory agents including romidepsin, pralatrexate, pralatrexate with bexarotene, bexarotene alone, and brentuximab vedotin. His biopsies (a total of 22) showed two distinct phenotypes: 1) lichenoid-like infiltrates composed primarily of lymphocytes and histiocytes with saw-toothing of rete ridges, colloid body formation, and variably present epidermotropic medium-sized atypical lymphocytes (Fig. 2a); or 2) a dense nodular granulomatous and lymphocytic dermal infiltrate (Fig. 2b). Immunohistochemistry demonstrated that the lymphocytic component was composed of CD3-positive, TCRß-expressing T-cells with a CD4:CD8 ratio of over 10:1, retained expression of $\mathrm{CD} 2, \mathrm{CD} 5$, and $\mathrm{CD} 7$, and $\mathrm{CD} 30$ expression in a minor subset. A subset of T-cells showed a cytotoxic profile with expression of CD56, TIA-1, granzyme, and perforin (Fig. 3). PD-1 was negative. Ebstein Barr virus (EBV) in situ hybridization was negative and immunohistochemistry for CD20 stained background B-cells. No definitive evidence for T-cell clonality was detected by conventional PCR of 6 biopsies and by NGS (Adaptive Biotechnologies, 1551 Eastlake Ave. E, Ste. 200, Seattle, WA 98102) of 14 biopsies (Fig. 4). Conventional PCR involved analysis for T-cell clonality and comparison of the clones using the BIOMED-2 primer set for TCR $\gamma$ chain (dual TCR-PCR) [8]. Six fluorescently labeled BIOMED-2 primers in two tubes allowed for the detection of nearly all $\mathrm{V} \gamma-\mathrm{J} \gamma$ combinations (Invivoscribe, Carlsbad, CA). After amplification, the PCR products were analyzed on an automated capillary electrophoresis system (ABI 3100, Applied Biosystems, Foster City, CA) with GeneScan software (Applied Biosystems). NGS-TCR by Adaptive involved qPCR amplification of TRB and TRG CDR3 (complementarity determining region 3 ), using tagged $\mathrm{V}$ - and Jgene primers, followed by sequencing of the amplified CDR3 regions. The PCR amplification was multiplexed with many $\mathrm{V}$-forward and J-reverse primers (specific to $T R B$ and TRG). The amplification bias was controlled by adjusting primer concentrations (based on their annealing properties) and adding to the PCR mixture a complete synthetic $\mathrm{V}(\mathrm{D}) \mathrm{J}$ template repertoire (with every possible V-J pair) at very low concentration to allow internal PCR calibration. After sequencing and enumerating all the TCR CDR3 regions, the residual bias was removed computationally. For a sequence to be considered dominant by this methodology, it must be $\geq 3 \%$ of all like sequences (TRB or TRG), $\geq 0.2 \%$ of the total nucleated cells in the sample, discontinuously distributed ( $\leq 5$ sequences in the next decade of sequences by frequency), and carried by $\geq 40$ estimated genome equivalents in the analyzed sample. TCR polyclonality was cughput sequencing was performed on his most recent biopsy using an in-house developed, clinically-validated NGS panel [Solid Tumor Actionable Mutation Panel for Hematopoietic and Lymphoid Malignancies (Heme- 


\section{Rank of 10 Most Prevalent TRB Sequences Over \\ $0.1 \%$ of Total Nucleated Cells}

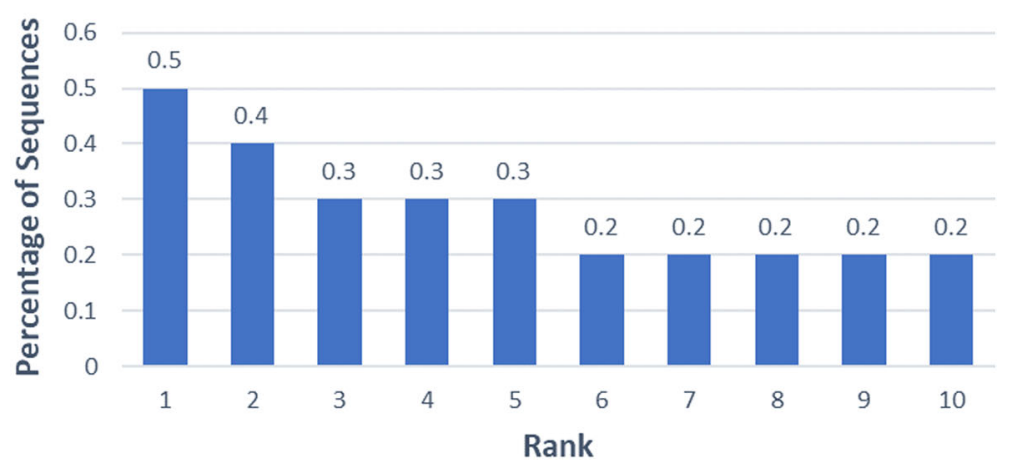

Rank of 10 Most Prevalent TRG Sequences Over $0.1 \%$ of Total Nucleated Cells

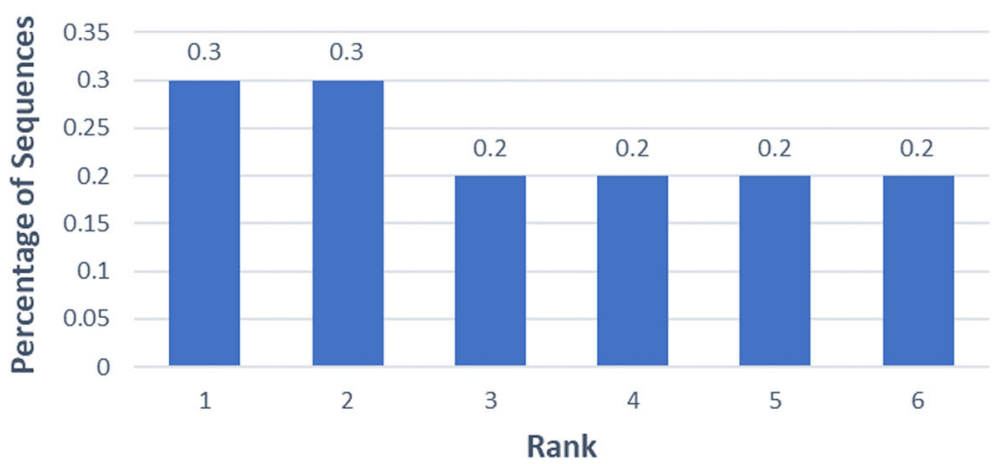

Fig. 4 Case 1. Rank of most prevalent sequences over $0.1 \%$ by next-generation sequencing of TRB (top) and TRG (bottom) for one skin biopsy

STAMP)] that covers 164 genes, either in part or fully, with the genes selected on the basis of their known impact as actionable targets of existing and emerging anti-cancer therapies, their prognostic features, and/or their mutation recurrence frequency across patients with known cancer types. The assay has a minimum analytic detection limit of at least $5 \%$ for single nucleotide variants and short insertion/deletions. The sequencing was performed on an Illumina ${ }^{\circ}$ NextSeq system. Bioinformatic analysis was performed using a pipeline developed and validated for clinical specimens. No paired normal tissue was available for comparison. Heme-STAMP identified three pathogenic mutations and their variant allele frequencies (VAF), including one in PIK3CD (c.3061G > A, p.E1021K, NM_005026.3, VAF $7 \%$ ), which encodes the delta subunit of phosphatidylinositol 3-kinase (PI3K) (Fig. 5). The PI3K pathway is one of the most commonly mutated pathways in cancer [9]. The E1021K mutation identified in this patient is an activating mutation in the kinase domain of the protein and is known to be associated with $\mathrm{B}$ cell lymphomas [10]. When present in the germline, this mutation is associated with a combined variable immunodeficiency disease known as activated PI3Kd syndrome, which can present with granulomatous skin lesions $[11,12]$. Other mutations in the PIK3CD gene have also been identified in hepatosplenic T-cell lymphomas [13]. Two additional mutations were in TERT (NM_198253.2) promoter hotspots (c.-146C $>$ T, VAF $6 \%$; c. $-124 \mathrm{C}>\mathrm{T}$, VAF $7 \%$, also referred to in the literature as $\mathrm{C} 250 \mathrm{~T}$ and $\mathrm{C} 228 \mathrm{~T}$, respectively) that lead to enhanced telomerase expression. Activating TERT promoter mutations are known to be associated with skin cancers including melanoma [14]. These pathogenic mutations support the clinical and histopathologic impression of CTCL. While awaiting possible allogeneic stem cell transplant, the patient has been stable or improving on pralatrexate (Fig. 1c-d), an antifolate chemotherapy considered standard of care for the treatment of CTCL $[15,16]$.

\section{Case 2}

A 69-year-old male was referred to our institution with a 13-year history of progressive hypertrophic and eroded 


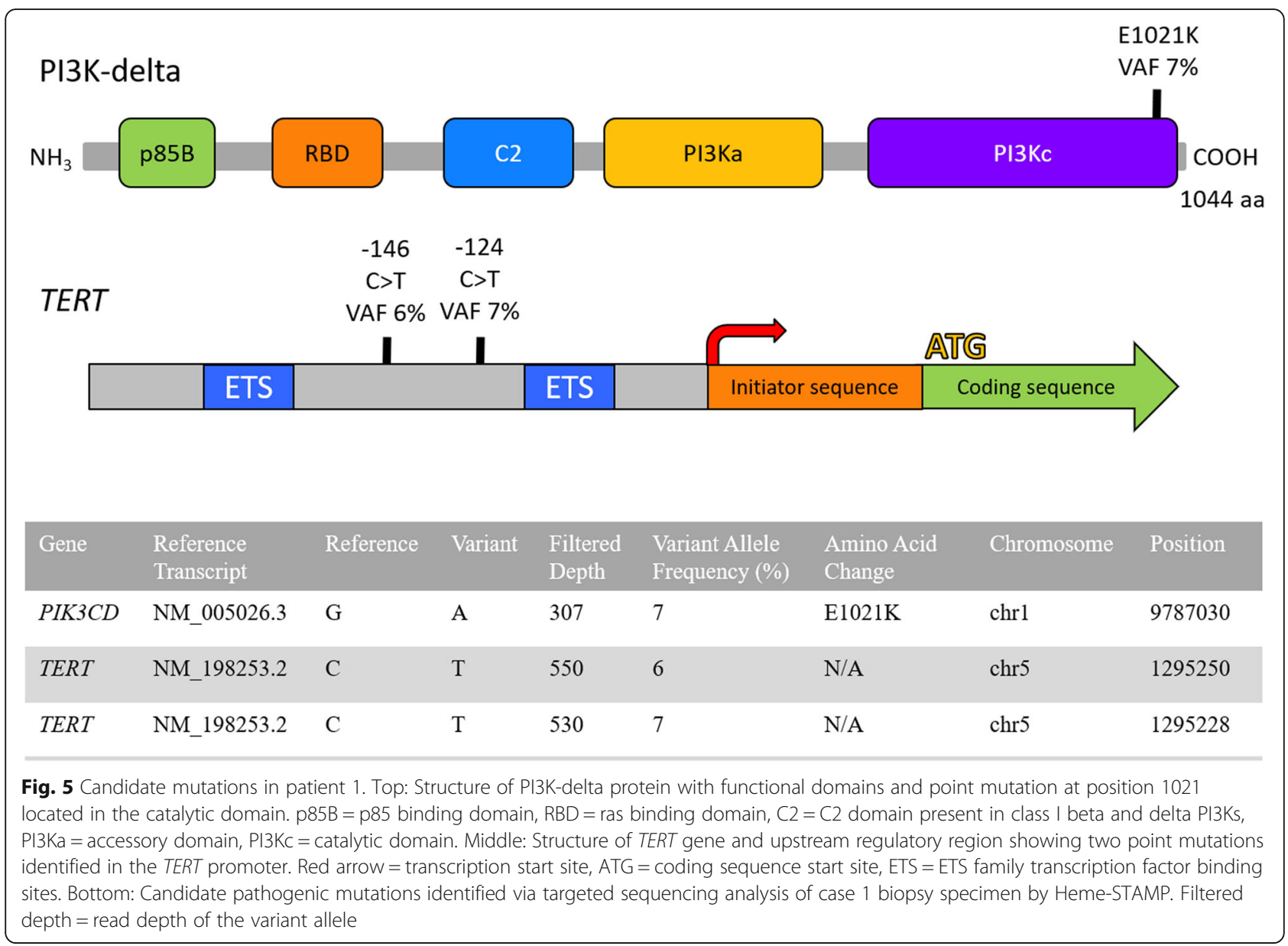

plaques present diffusely over the face, scalp, and entire body. Multiple biopsies showed epidermal hyperplasia with erosion and a dense lichenoid lymphocytic infiltrate that progressed over time to include a more significant epidermotropic component. Upon presentation at our institution, erosions were present on the posterior oropharynx and mucosal lip, and widely distributed ulcerated plaques and tumors were present on the face, scalp, back, and posterior arms (Fig. 6a-b). His treatments included total skin electron beam therapy, bexarotene, brentuximab, pembrolizumab, and pralatrexate with variable clinical response (Fig. 6c-d). His biopsies (a total of 17) showed acanthosis and mild spongiosis with dyskeratotic keratinocytes and an underlying dense lichenoid infiltrate of mostly small to medium-sized lymphocytes with convoluted nuclei extending around adnexal structures into the mid and deep dermis (Fig. 7a). Epidermotropism of haloed atypical lymphocytes including in intraepidermal clusters was increasingly prominent in his later biopsies, which also showed a progressively greater component of large atypical lymphocytes reflective of large cell transformation (Fig. 7b). Immunohistochemistry also showed a predominance of
CD3-positive T-cells expressing TCRß, with a CD4:CD8 ratio of at least 10:1 (Fig. 7c-e), with retained CD2 expression and partial loss of T-cell antigens CD5 and CD7. A subset of the cells (up to 15\%) expressed CD30 (Fig. 7f). PD-1 was negative. Immunohistochemistry for TIA1 and granzyme was positive in a subset of T-cells, CD56 was negative, and CD20 and MUM1 highlighted background B-cells. No TCR clonality was detected by NGS of 6 biopsies (Fig. 8). A biopsy specimen was sent for targeted NGS, which revealed a pathogenic mutation in TP53 (c.1028_1029del, p.E343fs*3, NM_000546.5, VAF 9\%) (Fig. 9). This mutation is predicted to result in a frameshift and early termination codon leading to loss of function of the tumor suppressor p53 [17]. TP53 is the most commonly mutated gene in human cancer, and mutations are typically associated with poor prognosis. This clonal mutation provides definitive support for classification as CTCL. The patient ultimately died due to complications of his disease.

\section{Discussion and conclusions}

We present two cases of CTCL with pathogenic somatic mutations in the setting of consistently polyclonal TCR 


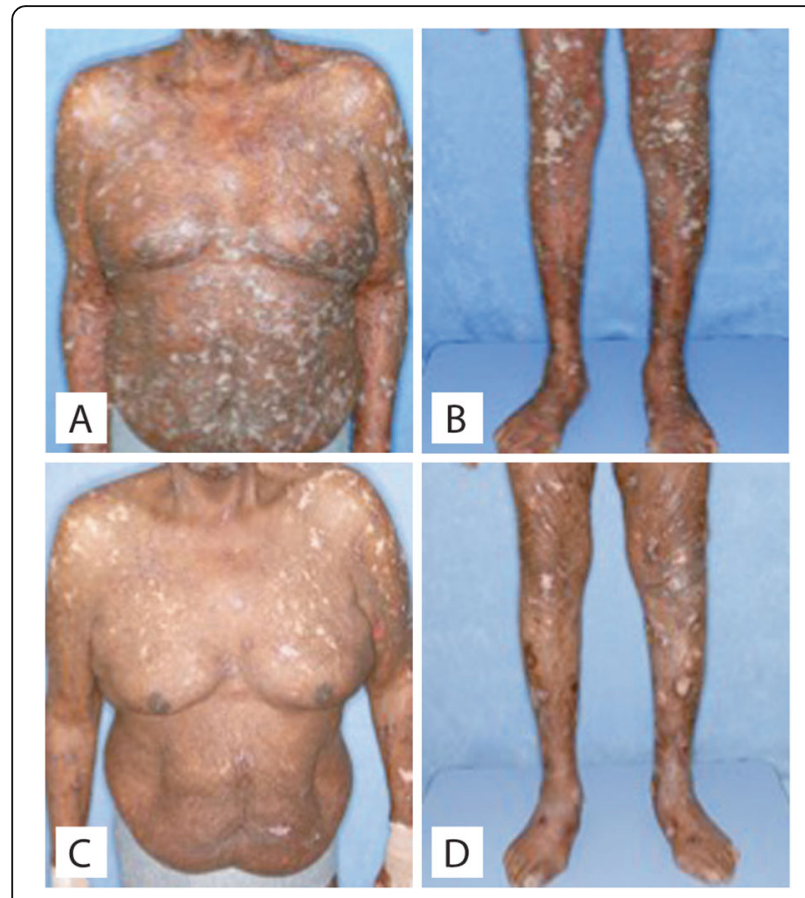

Fig. 6 Clinical photos of Case 2. $\mathbf{a}-\mathbf{b}$ Upon presentation at our institution. Diffuse erythematous hypertrophic and ulcerated papules and plaques. c-d Improvement after therapy

genes. Based on the clinical and histologic findings and the presence of pathogenic somatic mutations, we conclude that these cases are examples of true $\mathrm{T}$-cell lymphomas with repeatedly negative $\mathrm{T}$-cell receptor clonality studies performed by both conventional PCR as well as NGS. There are several potential hypotheses for why the TCR clonality assays are negative in these cases. One possibility is that the TCR genes are in a germline configuration and that these represent natural killer (NK)-cell lymphomas. However, immunohistochemical stains show that in both cases the infiltrates consist of numerous TCR $\beta$-positive, CD4-positive T-cells and that CD56 highlights, at most, a minority of the infiltrate. These findings strongly argue against NK-cell lymphoma. Another possible hypothesis is lack of sensitivity of the clonality assays. This is an unlikely contributor, however, as PCR-based clonality assays demonstrate a sensitivity of 0.1 to $1 \%$ [18] and NGS of TRB and TRG has even greater sensitivity and specificity than PCR [19]. Based on the histologic features and the VAFs of the pathogenic mutations in these cases (between 6 and 9\%), it is highly unlikely that a paucity of lymphoma cells or low proportion of lymphoma explains the negative clonality studies. We also considered that the negative TCR clonality in these cases is due to mutations that result in impaired primer binding or deletions, insertions, or rearrangements that otherwise affect the TRB and $T R G$ loci and prevent proper amplification during the PCR step of the assay. Also, some rare gene rearrangements may not be detected due to lack of included primers for rare $\mathrm{V}$ genes or due to disruption of primer binding sites by rare germline variants. We utilized an

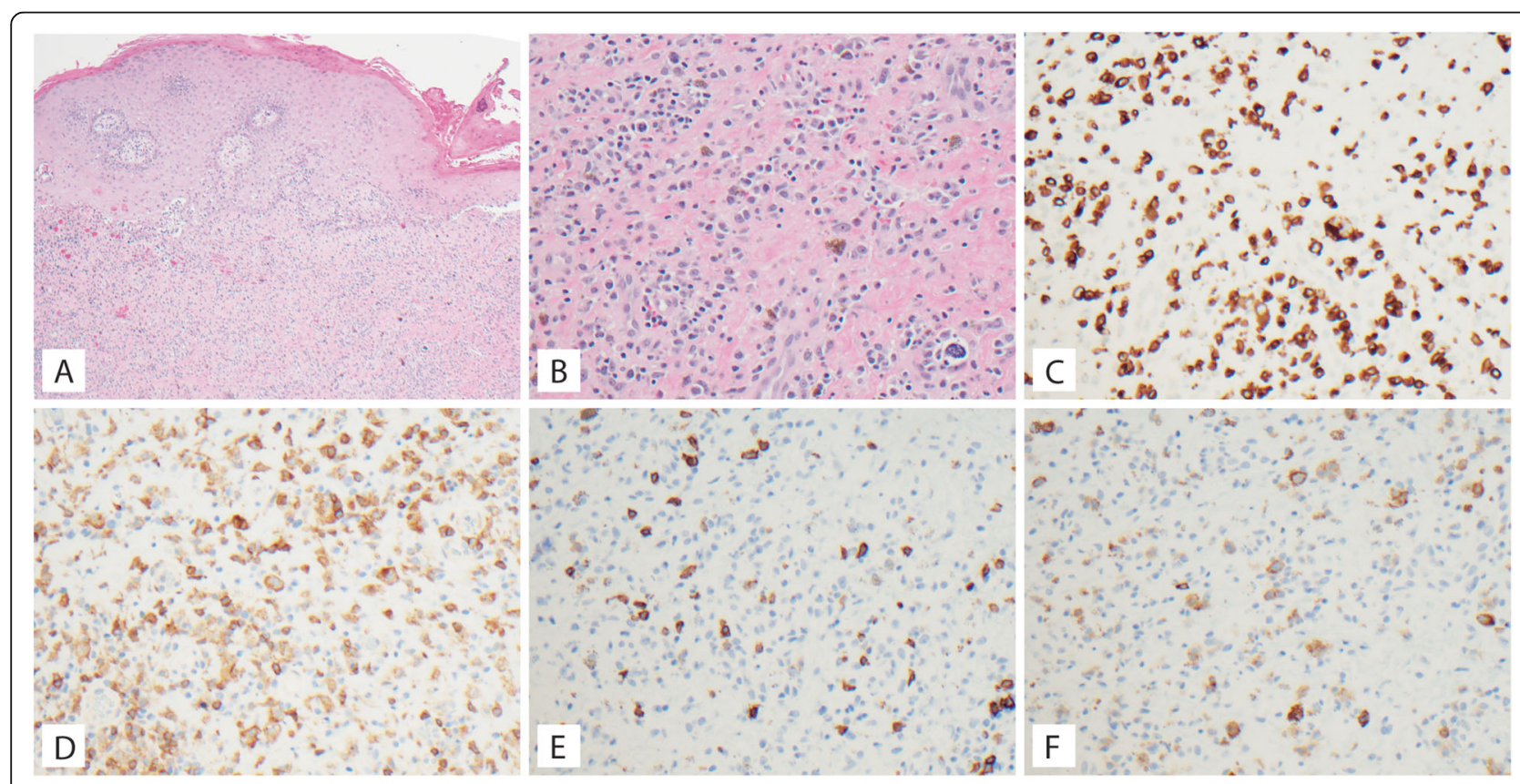

Fig. 7 Microscopic images of Case 2 biopsy of left upper back biopsy. a Skin with a dermal and epidermotropic infiltrate of atypical lymphocytes with irregularly contoured nuclei; H\&E 40X. b Higher power shows that a subset of cells is large in size; H\&E 200X. c CD3 immunostain; 200X. d CD4 immunostain; 200X. e CD8 immunostain; 200X. f CD30 immunostain; 200X 


\section{Rank of 10 Most Prevalent TRB Sequences Over \\ $0.1 \%$ of Total Nucleated Cells}

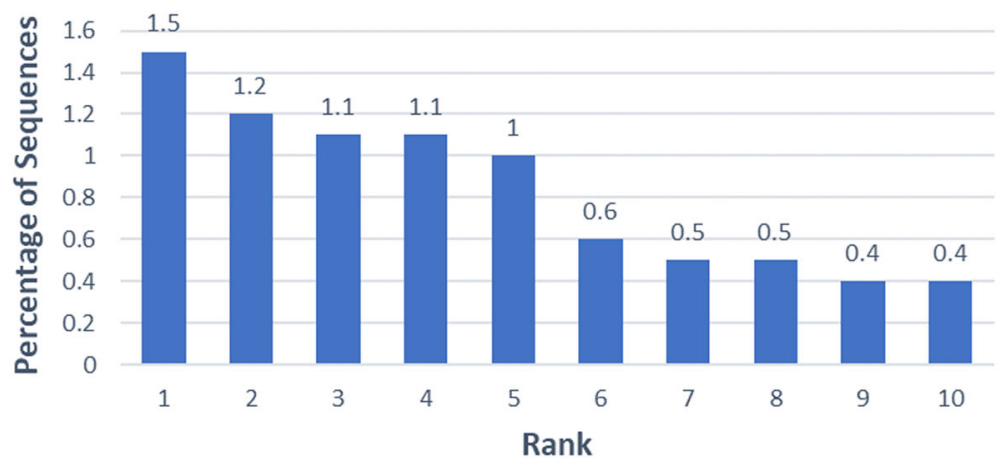

\section{Rank of 10 Most Prevalent TRG Sequences Over}

\section{$0.1 \%$ of Total Nucleated Cells}

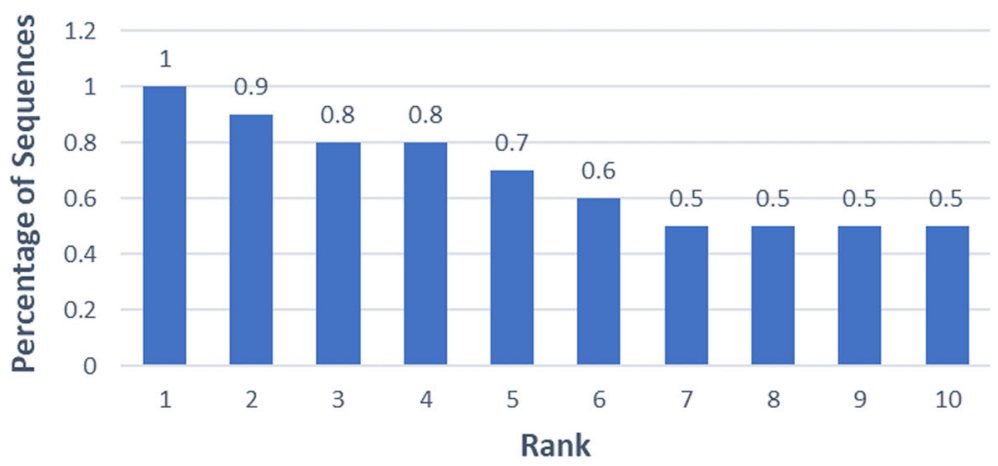

Fig. 8 Case 2. Rank of most prevalent sequences over $0.1 \%$ by next-generation sequencing of TRB (top) and TRG (bottom) for one skin biopsy

orthogonal method of RNAseq in one patient to test whether the lack of clonal rearrangement could be due to incompatibility with PCR based assays. Consistent with the clonality assays, we found polyclonal expression of TRB and TRA variable region genes and no clonal TCR gene rearrangements, although not all

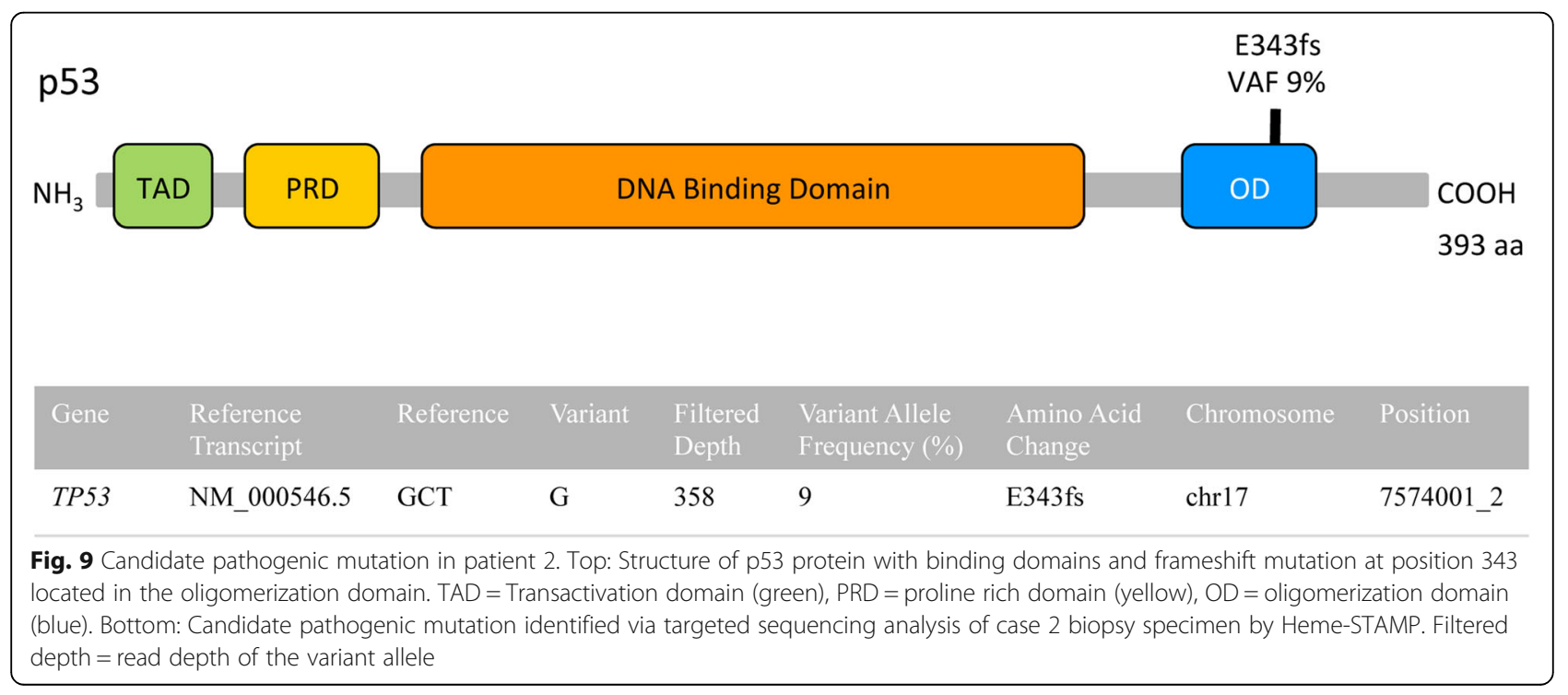


rearrangements are expressed. It is possible that these lymphomas may be truly polyclonal with respect to their TCR rearrangements, as has been previously proposed $[20,21]$. Although conventional wisdom dictates that $T C D$ sequencing would not be useful in this setting since this gene is deleted in $\alpha \beta \mathrm{T}$-cells, the potential utility of $T C D$ sequencing in similar cases warrants future exploration.

Cases such as the two presented here suggest that a diagnosis of a T-cell malignancy remains possible even with a polyclonal TCR-NGS result and even when the disease burden meets or exceeds the sensitivity threshold of the assay. In these cases, targeted NGS for somatic mutations can help clarify a diagnosis. The benefit of this type of sequencing is manifold. First, identification of pathogenic mutations strongly supports the presence of a neoplastic process. Second, even if no pathogenic mutations can be found, the presence of variants of unknown significance in similar allele frequencies not suggestive of germline variants (i.e. VAF near 50\%) may provide a somatic mutation signature that supports the presence of a clonal proliferation. These data can help arrive at a diagnosis of T-cell lymphoma even in the absence of detectable TCR gene rearrangement, and furthermore can help determine prognosis, guide therapy, and potentially monitor disease. For our second patient, mutations in TP53 have been associated with resistance to several chemotherapeutic medications and are the subject of active research involving small molecule modulators [22]. In the case of our first patient, multiple drugs targeting the PI3K pathway and associated AKT and mTOR pathways are already in clinical use and others are currently in clinical trials [23], making identification of this mutation potentially therapeutically informative. Further, the nodular granulomatous dermal infiltrates seen in this patient's biopsies share some features with the granulomatous lesions described in activated phosphoinositide 3-kinase delta syndrome, and could suggest possible mosaicism for the PIK3CD E1021K mutation.

Given our patients' pattern of involvement and CD4positive immunophenotype, diagnostic considerations include mycosis fungoides (MF), Sézary syndrome (SS), Tcell lymphomas with $\mathrm{T}$-follicular helper differentiation, such as angioimmunoblastic T-cell lymphoma or peripheral $\mathrm{T}$-cell lymphoma with $\mathrm{T}$ follicular helper differentiation, and peripheral T-cell lymphoma, not otherwise specified. The absence of PD-1 expression argues against a $\mathrm{T}$-cell lymphoma with T-follicular helper differentiation. Also, as at least $90 \%$ of Sezary syndromes and many cases of mycosis fungoides express this marker, absence of PD-1 expression and expression of cytotoxic markers raise the possibility that these two cases are phenotypically distinct from typical MF/SS cases [24-26].
To our knowledge, these two highly unusual cases are the first examples of using somatic mutational profiling to detect clonal populations in cutaneous T-cell lymphomas that lack detectable clonal T-cell receptor gene rearrangement. With study of additional cases, mutational profiling of abnormal T-cell lymphoproliferations may prove a useful diagnostic adjunct to results of clinical and histopathologic examination and TCR gene rearrangement testing.

\section{Abbreviations \\ CTCL: Cutaneous T-cell lymphoma; EBV: Epstein-Barr virus; Heme- STAMP: Solid Tumor Actionable Mutation Panel for Hematopoietic and Lymphoid Malignancies; MF: Mycosis fungoides; MRD: Minimal residual disease; NGS: Next-generation sequencing; NK: Natural killer; PCR: Polymerase chain reaction; SS: Sézary syndrome; TCR: T-cell receptor; TRB: T-cell receptor beta gene; TRG: T-cell receptor gamma gene; VAF: Variant allele frequency}

\section{Authors' contributions}

RR drafted the manuscript. YHK collected clinical histories. SFP, RAN, KER, and RAB performed histologic examination. MSK, JLZ, and CAK analyzed the data. RAB conceived the study. All authors read and revised the manuscript and approved the final version.

\section{Funding}

None

\section{Availability of data and materials}

The datasets used and/or analyzed during the current study are available from the corresponding author on reasonable request.

\section{Ethics approval and consent to participate}

This work was approved by the Institutional Review Board of Stanford University.

\section{Consent for publication}

The patient in Case 1 provided written informed consent for publication. The patient in Case 2 is deceased and informed consent was waived.

\section{Competing interests}

The authors declare that they have no competing interests.

\section{Author details}

'Department of Pathology, Stanford Medicine, Stanford, CA 94305, USA 2Department of Dermatology, Stanford Medicine, Stanford, CA 94305, USA. ${ }^{3}$ Division of Hematology, Department of Medicine, Stanford Medicine, Stanford, CA 94305, USA. ${ }^{4}$ Division of Oncology, Department of Medicine, Stanford Medicine, Stanford, CA 94305, USA. ${ }^{5}$ Department of Pathology, Veterans Affairs Palo Alto Health Care System, 3375 Hillview Ave, Room 1821, Palo Alto, CA 94304-1204, USA.

Received: 22 July 2020 Accepted: 2 September 2020

Published online: 28 September 2020

\section{References}

1. Willemze R, Cerroni L, Kempf W, Berti E, Facchetti F, Swerdlow SH, et al. The 2018 update of the WHO-EORTC classification for primary cutaneous lymphomas. Blood. 2019;133(16):1703-14.

2. van Dongen JJ, Wolvers-Tettero IL. Analysis of immunoglobulin and T cell receptor genes. Part II: possibilities and limitations in the diagnosis and management of lymphoproliferative diseases and related disorders. Clin Chim Acta. 1991;198(1-2):93-174.

3. Bergman R. How useful are T-cell receptor gene rearrangement studies as an adjunct to the histopathologic diagnosis of mycosis fungoides? Am J Dermatopathol. 1999:21(5):498-502.

4. Holm N, Flaig MJ, Yazdi AS, Sander CA. The value of molecular analysis by PCR in the diagnosis of cutaneous lymphocytic infiltrates. J Cutan Pathol. 2002;29(8):447-52 
5. Mahe E, Pugh T, Kamel-Reid S. T cell clonality assessment: past, present and future. J Clin Pathol. 2018;71(3):195-200.

6. Slater D. Clonal dermatoses: a conceptual and diagnostic dilemma. J Pathol. 1990;162(1):1-3.

7. Mielke V, Wolff HH, Winzer M, Sterry W. Localized and disseminated pagetoid reticulosis. Diagnostic immunophenotypical findings. Arch Dermatol. 1989;125(3):402.

8. Thurber SE, Zhang B, Kim YH, Schrijver I, Zehnder J, Kohler S. T-cell clonality analysis in biopsy specimens from two different skin sites shows high specificity in the diagnosis of patients with suggested mycosis fungoides. J Am Acad Dermatol. 2007;57(5):782-90.

9. Papa A, Pandolfi PP. The PTEN-PI3K Axis in Cancer. Biomolecules. 2019;9(4):153.

10. Kracker S, Curtis J, Ibrahim MAA, Sediva A, Salisbury J, Campr V, et al. Occurrence of B-cell lymphomas in patients with activated Phosphoinositide 3-kinase $\delta$ syndrome. J Allergy Clin Immunol. 2014;134(1): 233-6.

11. Nunes-Santos CJ, Uzel G, Rosenzweig SD. PI3K pathway defects leading to immunodeficiency and immune dysregulation. J Allergy Clin Immunol. 2019;143(5):1676-87.

12. Coulter TI, Chandra A, Bacon CM, Babar J, Curtis J, Screaton N, et al. Clinical spectrum and features of activated phosphoinositide 3-kinase $\delta$ syndrome: $\mathrm{A}$ large patient cohort study. J Allergy Clin Immunol. 2017;139(2):597-606 e4.

13. McKinney M, Moffitt AB, Gaulard P, Travert M, De Leval L, Nicolae A, et al. The genetic basis of hepatosplenic T-cell lymphoma. Cancer Discov. 2017; 7(4):369-79.

14. Huang FW, Hodis E, Xu MJ, Kryukov GV, Chin L, Garraway LA. Highly Recurrent TERT Promoter Mutations in Human Melanoma; 2013.

15. Hong JY, Yoon DH, Yoon SE, Kim SJ, Lee HS, Eom HS, et al. Pralatrexate in patients with recurrent or refractory peripheral T-cell lymphomas: a multicenter retrospective analysis. Sci Rep. 2019;9(1):20302.

16. National Comprehensive Cancer Network. Non-Hodgkin's Lymphomas (Version 3.2016). https:/jnccn.org/view/journals/jnccn/14/9/article-p1067.xml. .

17. Kim H, Kim K, Choi J, Heo K, Baek HJ, Roeder RG, et al. p53 requires an intact C-terminal domain for DNA binding and transactivation. J Mol Biol. 2012;415(5):843-54.

18. Bourguin A, Tung R, Galili N, Sklar J. Rapid, nonradioactive detection of clonal T-cell receptor gene rearrangements in lymphoid neoplasms. Proc Natl Acad Sci U S A. 1990;87(21):8536-40.

19. Hughes CF, Khot A, McCormack C, Lade S, Westerman DA, Twigger R, et al. Lack of durable disease control with chemotherapy for mycosis fungoides and Sézary syndrome: a comparative study of systemic therapy. Blood. 2015; 125(1):71-81.

20. Iyer A, Hennessey D, O'Keefe S, Patterson J, Wang W, Salopek T, et al. Clonotypic heterogeneity in cutaneous T-cell lymphoma (mycosis fungoides) revealed by comprehensive whole-exome sequencing. Blood Adv. 2019;3(7):1175-84

21. Iyer A, Hennessey D, O'Keefe S, Patterson J, Wang W, Wong GK, et al. Skin colonization by circulating neoplastic clones in cutaneous T-cell lymphoma. Blood. 2019;134(18):1517-27.

22. Hientz K, Mohr A, Bhakta-Guha D, Efferth T. The role of p53 in cancer drug resistance and targeted chemotherapy. Oncotarget. 2017;8(5):8921-46.

23. Wee S, Lengauer C, Wiederschain D. Class IA phosphoinositide 3-kinase isoforms and human tumorigenesis: implications for cancer drug discovery and development. Curr Opin Oncol. 2008;20(1):77-82.

24. Çetinözman F, Jansen PM, Willemze R. Expression of programmed death-1 in skin biopsies of benign inflammatory vs. lymphomatous erythroderma. $\mathrm{Br}$ J Dermatol. 2014;171(3):499-504.

25. Bosisio FM, Cerroni L. Expression of T-follicular helper markers in sequential biopsies of progressive mycosis fungoides and other primary cutaneous Tcell lymphomas. Am J Dermatopathol. 2015;37(2):115-21.

26. Dorfman DM, Brown JA, Shahsafaei A, Freeman GJ. Programmed death-1 (PD-1) is a marker of germinal center-associated T cells and angioimmunoblastic T-cell lymphoma. Am J Surg Pathol. 2006;30(7):802-10.

\section{Publisher's Note}

Springer Nature remains neutral with regard to jurisdictional claims in published maps and institutional affiliations.

Ready to submit your research? Choose BMC and benefit from:

- fast, convenient online submission

- thorough peer review by experienced researchers in your field

- rapid publication on acceptance

- support for research data, including large and complex data types

- gold Open Access which fosters wider collaboration and increased citations

- maximum visibility for your research: over $100 \mathrm{M}$ website views per year

At BMC, research is always in progress.

Learn more biomedcentral.com/submissions 